\title{
Numerical simulation of soil-cone penetrometer interaction using discrete element method
}

Krisztián Kotrocz ${ }^{\mathrm{a},}$, Abdul M. Mouazen ${ }^{\mathrm{b}}$, György Kerényi ${ }^{\mathrm{a}}$

${ }^{a}$ Department of Machine and Product Design, Budapest University

of Technology and Economics, Müegyetem rkp. 3., H-1111 Budapest, Hungary.

${ }^{\mathrm{b}}$ Cranfield Soil and AgriFood Institute, Cranfield University, Cranfield, MK43 OAL, UK.

* Corresponding author: Tel.: +361463 1371; fax: +3614633510

Email address: kotrocz.krisztian@gt3.bme.hu (K. Kotrocz)

\section{Abstract}

One of the most common methods to measure soil strength in-situ is cone penetrometers. In this paper the development of a three dimensional (3D) discrete element model (DEM) for the simulation of the soil-cone penetrometer interaction in a slightly cohesive loamy sand soil is presented. The aim was to investigate the effects of the soil model's geometrical (e.g., soil model cross section shape and size and model's height) changes on variations in the soil penetration resistance. The model area ratio and height ratio values were adopted to analyse the effects of the cross section size and the model's height, respectively. The results of penetration resistance of the DEM simulations were compared with the in-situ measurement with a cone penetrometer of the same geometry. This comparison allowed the derivation of the contact properties between the elements. To simulate the soil material the so-called Parallel Bond and Linear Models were used in the 3D version of the Particle Flow Code (PFC) software. Finally the mechanical properties of the soil, namely the cohesion and internal friction angle were estimated by DEM simulation of direct shear box.

Results showed that the penetration process can be simulated very well using the DEM. The model's calculated penetration resistance and the corresponding in-situ measurement were in good agreement, with mean error of $14.74 \%$. The best performing models were a rectangular model with an area ratio of 72 and a height ratio of 1.33 and a circular model with an area ratio of 32 and a height ratio of 2 . The simulation output of soil material properties with direct shear box resulted in representative values of real loamy sand soils, with cohesion values range of 6.61-8.66 $\mathrm{kPa}$ and internal friction angle values range of $41.34-41.60^{\circ}$. It can be concluded that the DEM can

Published by Elsevier. This is the Author Accepted Manuscript issued with: 
be successfully used to simulate the interaction between soil and cone penetrometers in agricultural soils.

Keywords: Discrete element method, cone penetrometer, soil mechanics.

\section{Introduction}

Soil compaction is the most known natural and manmade problem that negatively affects crop growth and yield, reduces soil hydraulic properties and increases soil susceptibility to erosion (Hamza and Anderson, 2005; Fleige and Horn, 2000). It directly results in increasing the cost of agriculture production due to the need for tillage operations (Garner et al., 1987; Mouazen and Ramon, 2002), which is a highly consuming energy operation. With the increase in agriculture machine size, machine mass tends to increase dramatically in the last few decades, which resulted in increasing the amount of normal stress applied into agriculture soils by both the driving and non-driving wheels and tracks. However, the traction produced under the driving wheels also leads to the generation of shear stress. Both the normal and shear stresses augment soil strength and as a result soil compaction is increased. One of the most common methods to measure soil strength is cone penetrometers.

Cone penetrometers are commonly used to measure the penetration resistance at a certain speed (McKyes, 1985), throughout the soil profile. The output of the measurement is the cone index (C. I.), which can be determined by dividing the penetration force to the cone projected area. The cone index depends on the soil properties, namely the water content, bulk density and particle size distribution (Sudduth et al., 2008). A second main reason to use cone penetrometers in the field is that they measure the bearing capacity of the soil, which is important not only in civil engineering projects but in agriculture too. Since penetrometers have small projected area of $1-2 \mathrm{~cm}^{2}$, they demand smaller penetration forces that can be provided by an operator (Laib, 2002). However, during field measurement penetrometers readings show high standard deviation, which is normally attributed to the heterogeneity of the soil, e.g., presence of stones or holes with the same dimension or bigger than the cone projected area (Sudduth et al., 2008; Fountas et al., 2013). This disadvantage can be compensated by performing high number of penetration tests on the same spot in the field (Laib, 2002), after which an average value can be calculated. However, performing multiple measurements on the same spot is a time consuming and costly 
operation. Therefore, efforts have been made to automatically measure penetration resistance, by utilising the tractor's three point linkage and hydraulic power. Multiple penetrometers were designed and combined with GPS receivers to obtain multiple measurements at the same time (Fountas et al., 2013).

Numerical simulation methods e.g., the finite element method (FEM) and discrete element method (DEM) are good alternative approaches to substitute the in-situ tedious, costly and time consuming experimental work. With the recent evolution of the information technology numerical simulations, particularly for soil-tillage and soil-wheel interaction become more popular (Mouazen and Neményi, 1998). The most common simulation methods used so far are FEM (Chi and Kushwaha, 1990; Kerényi, 1996; Mouazen and Neményi, 1999; Bentaher et al., 2013; Fervers, 2004), DEM (Shmulevich et al., 2007; Knuth et al., 2012; Tamás et al., 2013) and computational fluid dynamics (CFD) (Formato et al., 2005). The FEM has been used to simulate both homogenous (e.g. Chi and Kushwaha, 1990) and non-homogeneous (e.g. Mouazen and Neményi, 1998) soil material, modelled as a continuum. Less effort was reported on the simulation of soil penetration (Tekeste et al., 2007; Foster Jr. et al., 2005). Since soil consists of individual particles of different size, the simulation is more appropriate to be done with the DEM, established by Cundall and Strack (1979). This method can be used to simulate granular assemblies because the material is modelled as a group of individual elements with their contacts. DEM has been used in several agricultural fields, e.g. to model the interaction between soil and tillage tools (e.g., Tamás et al., 2013; Chen et al., 2013), and to simulate the material overflow and the discharging process from silos (e.g., Keppler et al., 2012; Goda and Ebert, 2005). There are also several published works about the simulation of the soil-wheel interaction using the DEM (Smith and Peng, 2013; Khot et al., 2007). Many research works were published about the use of the DEM to study the dynamic motion of the Mars rover's or the lunar rover's wheel (Knuth et al., 2012; Nakashima et al., 2010). To our best knowledge only limited research on the simulation of the soilcone penetrometer was reported in the literature, particularly in agricultural soils. Wang and Zhao (2014) and Tanaka et al. (2000) used the DEM to simulate this phenomenon in two dimension (2D) and Butlanska et. al. (2014) and Lin and Wu (2012) in three dimension (3D) but only for non-cohesive soils. Arroyo et. al (2009) investigated the effects of homogeneity and symmetry of the discrete element model on cone penetration and experienced differences in the soil resistance 
between, the half, quarter and full size model. Furthermore, large portion of error in DEM simulations is attributed to the difficulties associated with the determination of contacts properties between soil particles at micro scale correctly, which necessitates further research to accurately determine these contact properties.

This paper aims at the development of a 3D DEM model for the simulation of the soil penetration with a cone penetrometer in a slightly cohesive loamy sand soil. It will aim at the optimisation of the dimensions of the soil model (shape and size of the cross section and model height) for accurate prediction of penetration resistance.

\section{Development of the discrete element model}

\subsection{In-situ tests}

In-situ tests for the measurement of penetration resistance were performed at the experimental farm of Szent István University of Gödöllő (Máthé et al., 2013, Máthé, 2014), using a standard Eijkelkamp penetrologger (Eijkelkamp, Netherland) in the track of the GAZ-69 (69A) type of vehicle.

The cone's bevel angle was $60^{\circ}$ and its projected area was $0.0002 \mathrm{~m}^{2}$ (see Fig. 1). Two measurement series with 10 repetitions each were performed, namely one series in front of the left wheel and one in front of the right wheel of the vehicle pushing the penetrometer with velocity of $0.01 \mathrm{~m} \mathrm{~s}^{-1}$ into the soil. The 10 measurement of each series were averaged in one value. According to the results of the measurements the soil penetration resistance has high standard deviation of $0.48 \mathrm{MPa}$, $0.55 \mathrm{MPa}$ and $0.52 \mathrm{MPa}$ at depth of $0.05 \mathrm{~m}, 0.1 \mathrm{~m}$ and $0.15 \mathrm{~m}$, respectively, which can be experienced in real soils (Laib, 2002; Sudduth et al., 2008; Fountas et al., 2013). During penetration resistance measurement, soil samples were collected with core cylinders to determine the average bulk density, moisture content and porosity (Table 1).

Table 1. The measured soil properties at the time of penetration resistance measurement (Máthé et al., 2013, Máthé, 2014).

\begin{tabular}{ll}
\hline Parameter & Value \\
\hline Soil type (-) & Loamy sand with $90,5 \%$ sand, \\
& $3,2 \%$ silt and $6,3 \%$ clay \\
Bulk density $\left(\mathrm{kg} \mathrm{m}^{-3}\right)$ & 1632 \\
Moisture content $(\%$ dry basis) & 15.8 \\
Porosity (-) & 0.36 \\
\hline
\end{tabular}

2.2. Construction of discrete element model 
The simulation of soil penetration with the same cone penetrometer of Eijkelkamp penetrologger (Eijkelkamp, Netherland) was carried out using the Particle Flow Code software (PFC3D ITASCA ${ }^{\text {TM }}$, USA). In the PFC3D software the material can be modelled using only rigid ball elements. Each particle can be in contact with the adjacent balls and walls. If a contact exists between two elements (ball and ball or ball and wall) the contact force can be calculated from the stiffness and the relative position of the contacting elements (Potyondy and Cundall, 2004). Afterwards, the displacement of each element is determined according to the Newton's second law, expressed by the following two vector equations (Itasca, 1999):

$$
F_{i}=m \cdot\left(\ddot{x}_{i}-g_{i}\right)
$$

for translational motion, where $F_{i}$ is the resultant force (the sum of the all externally applied forces acting on the particle) in $\mathrm{N}$, $m$ is the total mass of the particle in $\mathrm{kg}, \ddot{x}_{i}$ is the acceleration of the particle in $\mathrm{m} \mathrm{s}^{-2}$ and $g_{i}$ is the gravity loading in $\mathrm{m} \mathrm{s}^{-2}$.

For rotational motion, the following equations were used, which can be written when the particle's local coordinate system lies along the principal axes of inertia of the particle:

$$
\begin{aligned}
& M_{1}=I_{1} \cdot \dot{\omega}_{1}+\left(I_{3}-I_{2}\right) \cdot \omega_{3} \cdot \omega_{2} \\
& M_{2}=I_{2} \cdot \dot{\omega}_{2}+\left(I_{1}-I_{3}\right) \cdot \omega_{1} \cdot \omega_{3} \\
& M_{3}=I_{3} \cdot \dot{\omega}_{3}+\left(I_{2}-I_{1}\right) \cdot \omega_{2} \cdot \omega_{1}
\end{aligned}
$$

where $M_{1}, M_{2}, M_{3}$ are the components of the resultant moment acting on the particle referred to the principal axes in $\mathrm{N} \mathrm{m}, I_{1}$, $I_{2}, I_{3}$ are the principal moments of inertia of the particle in $\mathrm{kg} \mathrm{m}^{2}$ and $\dot{\omega}_{1}, \dot{\omega}_{2}, \dot{\omega}_{3}$ are the angular accelerations about the principal axes in $\mathrm{rad} \mathrm{s}^{-2}$. These two vector equations are integrated using the centred finite difference procedure involving timestep of $\Delta t$, resulting the velocities (translational and rotational), which are used to update the positions and the structure of the particles. Finally, the whole iteration process is repeated from the beginning so that the displacements of the elements can be calculated in every timestep.

The DEM simulations of soil penetration were performed with rectangular and circular cross section models (Fig. 1). During DEM model construction several steps were followed to set up the final model. Firstly, a huge number of particles (in the range of 3378 to 24585 depending on the model's dimensions) were generated in the rectangular and circular shapes of soil body and poured to the bottom under earth gravity. The 
geometry of the soil body was changed in each simulation to investigate the effect of the soil body dimensions and shape on soil penetration resistance. The diameters of the circular cross sections were chosen so as to provide the same area of that of the rectangular cross section models, as to allow for correct comparison between the two models output. Thus, the area of the rectangular cross section model was $0.06 \mathrm{~m}$ by $0.06 \mathrm{~m}$ which was equal to the circular cross section model with a diameter of $\varnothing 0.0677 \mathrm{~m}$ and so on. The area ratio calculated as the ratio of the area of the model's cross section divided by the projected area of the penetrometer cone $\left(0.0002 \mathrm{~m}^{2}\right)$ was considered for further analysis to understand the effect of the shape and size of the model's cross section on penetration resistance. Finally, the height of the soil model was changed for $0.2 \mathrm{~m}, 0.25 \mathrm{~m}, 0.3 \mathrm{~m}$ and $0.35 \mathrm{~m}$. The height ratio calculated by dividing the model's height with the penetration depth $(0.15 \mathrm{~m})$ was also considered in the simulation. Figure 1 illustrates the initial geometry of two individual models where only one half of the model is shown to visualise the parallel bonds in the central plan. In this figure the dimensions of the cone penetrometer used in the simulation can be seen as well.

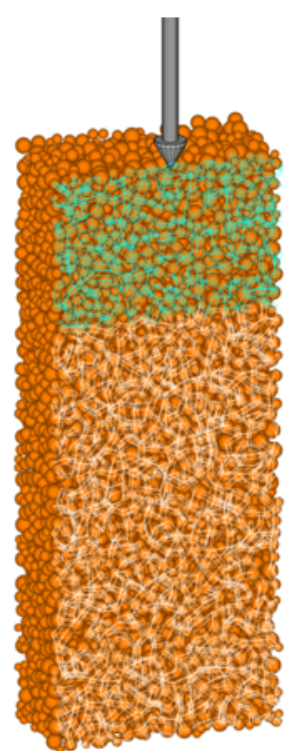

a)

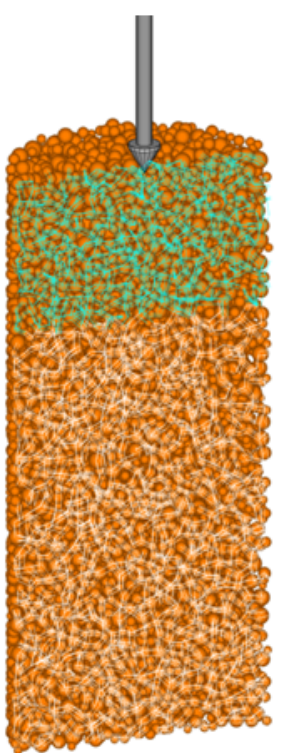

b)

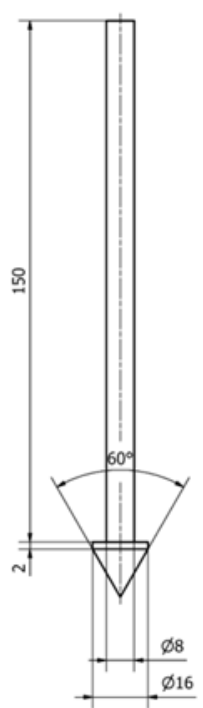

c)

Figure 1. The three-dimensional (3D) discrete element model (DEM) initial geometry of the rectangular cross section (a) with a model dimension of $0.12 \mathrm{~m}$ by $0.12 \mathrm{~m}$ by $0.30 \mathrm{~m}$, the circular cross section (b) with a model dimension of $\varnothing 0.1354 \mathrm{~m}$ by $0.30 \mathrm{~m}$ and the dimensions of the cone penetrometer in $\mathrm{mm}$ (c). Parallel bond contacts are represented as white and cyan lines in the central plan of the models in (a) and (b).

After the DEM model was established, the contact properties of soil particles shown in Table 2 were assigned between the elements. In PFC3D code, the contacts between the elements 
play an important role because only rigid elements can be generated. Therefore, the material properties can be modelled correctly if sufficient contact and accurate contact parameters are assigned between the particles. To simulate the interaction between particles of real soil, the Linear Model and Parallel Bond Model available in the PFC3D code were used. The Linear Model was responsible to represent the friction between the particles. Therefore in each contact, the contact force vector $\left(F_{i}\right)$ can be resolved into normal $\left(F_{i}^{n}\right)$ and shear $\left(F_{i}^{S}\right)$ components with respect to the contact plane defined by the unit vectors $\left(n_{i}\right.$ and $\left.t_{i}\right)$ as follows (Potyondy and Cundall, 2004):

254 The normal component $\left(F^{n}\right)$ of the contact force can be 255 calculated by (Potyondy and Cundall, 2004):

257 where $K^{n}$ denotes the normal stiffness between the contacting 258 elements in $\mathrm{N} \mathrm{m}^{-1}$ and $U^{n}$ is the overlap of the contacting 259 elements in meter. The new shear force $\left(F^{s}\right)$ at the end of the $\Delta t$ 260 timestep can be calculated in an incremental fashion with the 261 shear elastic force increment $\left(\Delta F^{S}\right)$ using the following formula 262 (Potyondy and Cundall, 2004):

$$
F^{s}=F_{\text {old }}^{s}+\Delta F^{s} \leq \mu \cdot F^{n}=F_{\max }^{s}
$$

264

265

266

267

268

269

270

271

272

where $F_{\text {old }}^{s}$ is the shear force from the previous timestep in $\mathrm{N}$ and $\mu$ is the dimensionless friction coefficient between the particles. If the new shear force is greater than the maximum allowable shear contact force $\left(F_{\max }^{s}\right)$ slip is allowed to occur in the next timestep between the contacting elements. The shear elastic force increment can be determined with the contact shear stiffness $\left(k^{s}\right)$ and the shear displacement increment $\left(\Delta U^{s}\right)$ occurring over a timestep of $\Delta t$ (Potyondy and Cundall, 2004):

$\Delta F^{s}=-k^{s} \cdot \Delta U^{s}$.

The only difference between Formula 4 and Formula 6 is that the shear force is calculated in increment form with the tangent stiffness modulus $\left(k^{s}\right)$ in each timestep, while the normal contact force relates the total displacement and total force of the particle, which can be interpreted with the numerical stability. The computation of the normal force only from the geometry makes the code less prone to numerical drift (Potyondy and Cundall, 2004). 


$$
\tau_{\max }=\frac{\left|\bar{F}^{s}\right|}{A}+\frac{\left|\bar{M}^{n}\right|}{J} \cdot \bar{R}
$$

291 where $\bar{F}^{n}, \bar{F}^{s}, \bar{M}^{s}, \bar{M}^{n}$ are the normal- and shear contact force 292 in N, axial- and shear directed moments in $\mathrm{N} \mathrm{m}$, respectively. $293 A, I$ and $J$ denote to the area in $\mathrm{m}^{2}$, the moment of inertia and 294 the polar moment of inertia of the parallel bond cross section in $295 \mathrm{~m}^{4}$, respectively. If the maximum normal stress exceeds the 296 parallel bond normal strength or the maximum shear stress 297 exceeds the parallel bond shear strength the parallel bond 298 breaks between the two contacting elements (Potyondy and 299 Cundall, 2004).

300 To implement these two contact models, the contact properties 301 (shown in Table 2) between the soil particles need to be 302 determined to give accurate results in soil penetration resistance 303 compared to the in-situ measurements. The values of the 304 normal and shear ball stiffness were assumed equal. After that a 305 large number of simulations were performed with manually 306 modified contact properties to investigate the effect of the 307 individual parameters (ball stiffness and the parallel bond 308 strengths and stiffness) on the penetration resistance. After each 309 simulation the calculated soil penetration resistances were 310 compared to the measurement values and the contact 311 parameters were modified to provide similar soil resistance 312 variations to that of the in-situ. This was repeated 313 approximately the 60th to achieve convergence. The results of 314 the calibrational process are shown in Table 2.

315 Table 2. The material properties of the discrete element models (DEM), 316 derived from the DEM penetration simulations.

\begin{tabular}{ll}
\hline Parameter & Value \\
\hline Bulk density $\left(\mathrm{kg} \mathrm{m}^{-3}\right)$ & 1632 \\
Particle radius distribution $(\mathrm{m})$ & $0.002-0.0045$ \\
Porosity $(\%)$ & $0.413 \ldots 0.439$ \\
\hline
\end{tabular}




\begin{tabular}{|c|c|}
\hline Ball normal stiffness $(\mathrm{kn})\left(\mathrm{N} \mathrm{m}^{-1}\right)$ & $1 \mathrm{e} 6$ \\
\hline Ball shear stiffness $(\mathrm{ks})\left(\mathrm{N} \mathrm{m}^{-1}\right)$ & $1 \mathrm{e} 6$ \\
\hline Penetrometer normal stiffness $\left(\mathrm{N} \mathrm{m}^{-1}\right)$ & $1 \mathrm{e} 10$ \\
\hline Penetrometer shear stiffness $\left(\mathrm{N} \mathrm{m}^{-1}\right)$ & $1 \mathrm{e} 10$ \\
\hline Local damp constant $(\alpha)(-)$ & 0.3 \\
\hline $\begin{array}{l}\text { Friction coefficient between ball and ball } \\
\left(\mu_{\text {ball }}\right)(-)\end{array}$ & 0.6 \\
\hline $\begin{array}{l}\text { Friction coefficient between ball and } \\
\text { cone penetrometer }(\mu)(-)\end{array}$ & 0.5 \\
\hline Timestep range (s) & $1.9 e-6-2.6 e-6$ \\
\hline \multicolumn{2}{|l|}{$\begin{array}{l}\text { Parallel Bond parameters (results of the } \\
\text { iteration) }\end{array}$} \\
\hline Parallel Bond radius (pb_rad) (-) & 0.5 \\
\hline $\begin{array}{l}\text { Parallel Bond normal stiffness (pb_kn) } \\
\left(\mathrm{Pa} \mathrm{m}^{-1}\right)\end{array}$ & $5.25 \mathrm{e} 7$ \\
\hline $\begin{array}{l}\text { Parallel Bond shear stiffness (pb_ks) } \\
\left(\mathrm{Pa} \mathrm{m}^{-1}\right)\end{array}$ & $5.25 \mathrm{e} 7$ \\
\hline $\begin{array}{l}\text { Parallel Bond normal strength in the top } \\
\text { layer (pb_n) (Pa) }\end{array}$ & $4.27 \mathrm{e} 5$ \\
\hline $\begin{array}{l}\text { Parallel Bond shear strength in the top } \\
\text { layer }\left(\mathrm{pb} \_\mathrm{s}\right)(\mathrm{Pa})\end{array}$ & $4.27 \mathrm{e} 5$ \\
\hline $\begin{array}{l}\text { Parallel Bond normal strength in the } \\
\text { bottom layer }(\mathrm{pb} n)(\mathrm{Pa})\end{array}$ & $6.4 \mathrm{e} 5$ \\
\hline $\begin{array}{l}\text { Parallel Bond shear strength in the } \\
\text { bottom layer }(\mathrm{pb} s)(\mathrm{Pa})\end{array}$ & $6.4 \mathrm{e} 5$ \\
\hline
\end{tabular}

318 The soil model was divided into two sections. In the top section 319 down to $0.08 \mathrm{~m}$ depth, the parallel bonds were assigned smaller 320 normal- and shear strength, whereas elements in the bottom 321 layer were assigned higher material parameters (Table 2 and 322 Fig. 1). This was done in order to simulate the actual soil 323 strength encountered in the field, where the top layer is 324 subjected to lower normal stresses as compared to deeper 325 layers.

326 The cone penetrometer was placed on the top of the soil 327 surface, and was moved downwards throughout the soil body 328 down to $0.15 \mathrm{~m}$ depth with the same velocity as in the in-situ 329 measurements $\left(0.01 \mathrm{~m} \mathrm{~s}^{-1}\right)$, while soil resistance to penetration 330 was calculated at each $1000^{\text {th }}$ calculation cycle. The timestep 331 was set to "auto" to guarantee the mathematical stability of the 332 calculation (Itasca, 1999). Thus the value of the timestep was 333 automatically modified in every calculation timestep, within 334 approximate range of $1.9 \cdot 10^{-6}-2.6 \cdot 10^{-6} \mathrm{~s}$.

335 Spherical elements were used in the calculations. It is well 336 known that the shape of the particles plays an important role in 337 the DEM simulations (Falagush et.al., 2015 and 
Nakashima et al., 2013). In our simulations the Parallel Bond contact force presents (cohesive soil) to capture the rotational resistance of the spherical elements in the simulations.

\subsection{Discrete element model of direct shear test}

In earlier research by Tamás et al. (2013) and Sadek et al. (2011), direct shear tests were simulated to determine the mechanical parameters of the soil, namely, Mohr-Coulomb properties of cohesion and angle of internal friction. Similar approach was adopted in the current work. DEM simulations of the direct shear tests were performed to estimate the soil cohesion and internal friction angle. Comparison between the simulation and laboratory tests results could not to be done because direct shear tests were not performed at the time of penetration resistance measurements. The estimation of the soil's mechanical properties was done based on Mohr-Coulomb law, which describes a linear relationship between the maximum of the horizontal (shear) $\left(T_{f}\right)$ and the normal forces (N) (Terzaghi, 1943):

$T_{f}=c \cdot A+N \cdot \tan \varphi$

where $c$ refers the cohesion in $\mathrm{MPa}, A$ is the sheared area in $\mathrm{mm}^{2}$ and $\varphi$ means the angle of internal friction of the soil sample in degree $\left[^{\circ}\right]$.

The dimension of the shear box test was set to be of $0.06 \mathrm{~m}$ by $0.06 \mathrm{~m}$ by $0.0508 \mathrm{~m}$ so that the area of the cross section was $0.06 \mathrm{~m}$ by $0.06 \mathrm{~m}=0.0036 \mathrm{~m}^{2}$. The same contact properties were set in the simulation to that of used in the soilpenetration simulations. The top half of the soil sample in the shear box was subjected to downward vertical forces (e.g. the normal force, $N$ ), while the top section was moved horizontally, as shown in Fig. 2. In this figure the parallel bonds were represented as white lines. During the simulations the horizontal and vertical displacement of the box and the shear force $(T)$ were calculated at each $500^{\text {th }}$ calculation cycle. The DEM simulations of the direct shear test were performed with the top layer of the soil model (assigned parallel bond strength of $4.27 \mathrm{e} 5 \mathrm{~Pa}$ (Table 2) subjected to normal loads of $480 \mathrm{~N}$, $615 \mathrm{~N}, 750 \mathrm{~N}$ and $885 \mathrm{~N}$, respectively. The calculations were performed with the bottom soil model layer assigned larger parallel bond strength of $6.4 \mathrm{e} 5 \mathrm{~Pa}$ (Table 2) as well. 


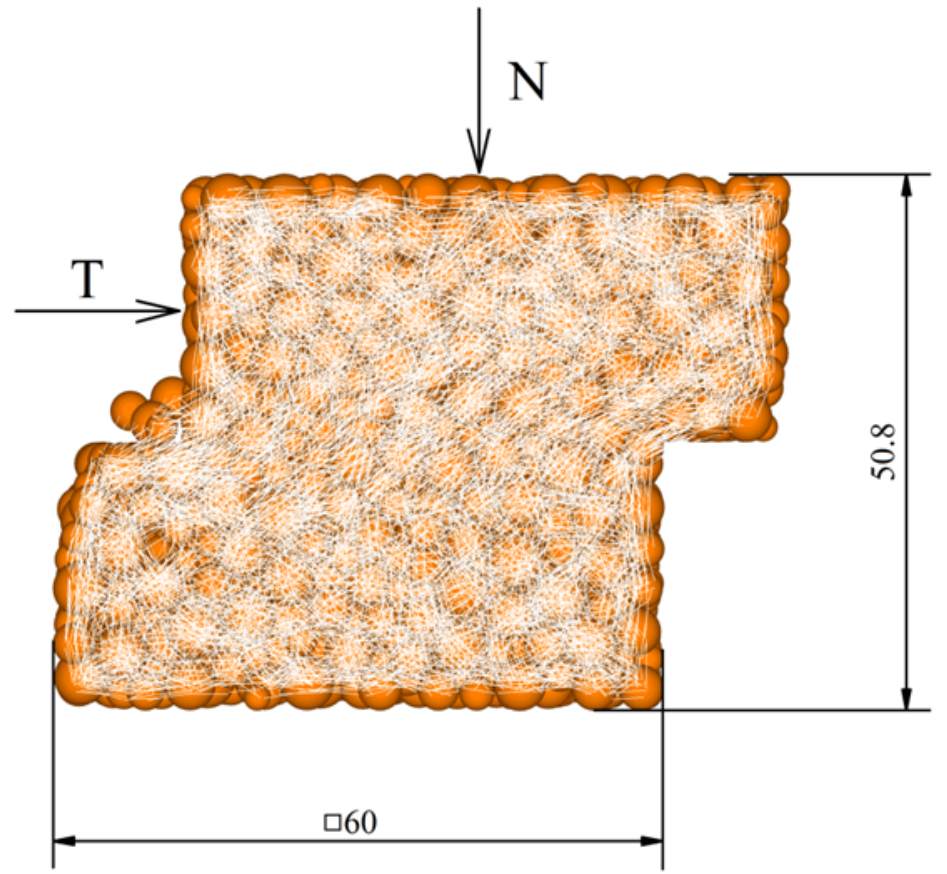

Figure 2. Discrete element method (DEM) simulation of the direct shear box test. Parallel bond contacts are represented as white lines and the dimensions are in $\mathrm{mm}$.

\section{Results and discussion}

\subsection{Qualitative estimation of the soil penetration}

According to the experimental work, the maximum displacement of the soil particles takes place near and ahead of the cone penetrometer (Tanaka et al., 2000 and Foster Jr. et al., 2005). The DEM output for displacement, shown in Fig. $3 b$ shows a similar pattern of particles movement to that of the experiment. According to Tanaka et al. (2000) the elements near the penetrometer cone and shaft moved downward following the movement of the penetrometer because of the high coefficient of friction value between the soil particles and the cone penetrometer. A maximum displacement of $0.015 \mathrm{~m}$ was calculated for few elements that are in direct contact with the penetrometer cone and shaft. It was predictable as well that the particles' greatest velocity at given timestep will be around the head of the cone, which can be observed in Fig. 3c. Figure $3 \mathrm{a}$ also shows the broken parallel bonds in front of and near the head of the penetrometer cone due to the failure of these bonds by the forces exerted by the penetrometer cone. The soil failure process under the tip of the penetrometer cone is not known in detail but it can be assumed that the soil failures occur approximately where the parallel bonds break in the discrete element model. 


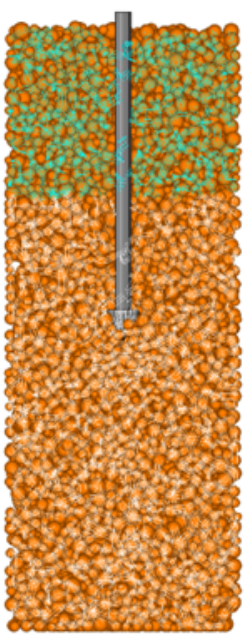

a)

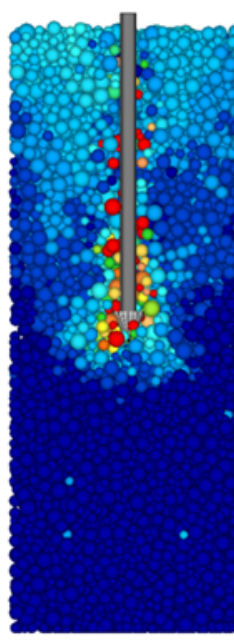

b)

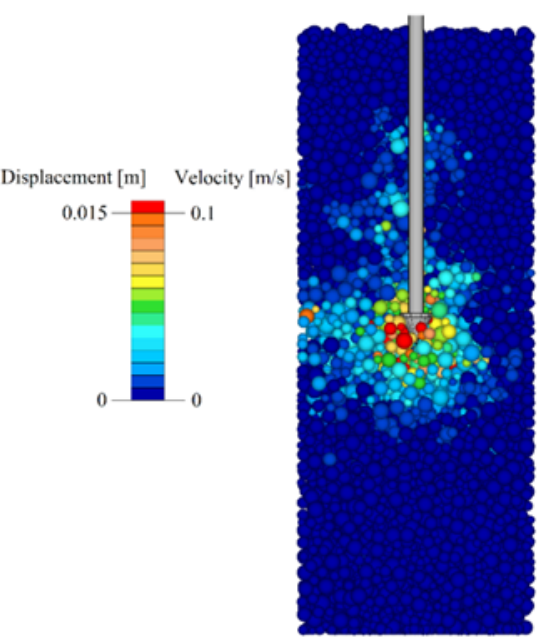

c)
405

406

407

408

409

410

411

412

413

414

415

416

417

418

419

420

421

422

423

424

425

426

427

428

429

430

431

432

433

Figure 3. The result of the discrete element method (DEM) numerical simulation of the penetration test, shown for a rectangular cross section with a soil body cross-section of $0.12 \mathrm{~m}$ by $0.12 \mathrm{~m}$ and height of $0.30 \mathrm{~m}$ : a) front view of the DEM model, showing the broken parallel bonds, b) elements displacement distribution and c) elements velocity distribution.

\subsection{Quantitative estimation of the soil penetration resistance}

The calculated soil penetration resistance was illustrated as a function of the cone's vertical displacement, which can be observed in Fig. 4 for a rectangular cross section of $0.12 \mathrm{~m}$ by $0.12 \mathrm{~m}$ and a height of $0.30 \mathrm{~m}$. Results show that the calculated penetration resistance matches the average measured soil resistance, which indicates a realistic model approximation of in-situ soil penetration.

Similar to previous works (Tanaka et al., 2000 and Foster Jr. et al., 2005), the simulated penetration resistance fluctuated considerably, with larger fluctuation observed with increased depth (Foster Jr. et al., 2005). The reason of this result could be the large diameter of the soil particles (Tanaka et al., 2000). The number of contacting elements with the tip of the cone was counted as well in order to check to get enough balls around the tip and correct soil resistance variations, this data varied in the range of $10 \ldots 20$ in the simulations. To investigate the accuracy of the individual simulations a trend-line calculated using the Ordinary Least Squares available in the Microsoft Excel 2013 software was fitted to the simulation values, with a high $\mathrm{R}^{2}$ value of 0.91 . The mean error ( $\overline{R E}$ in \%) of the trend-line and the average soil penetration resistance was calculated according to Sadek et al. (2011):

$\overline{R E}=\frac{\sum_{1}^{n} \frac{C I_{D E M}-C I_{\text {in-situ }}}{C I_{\text {in-situ }}}}{n} \cdot 100$ 
where the $C I_{D E M}$ is the soil resistance calculated from the trendline of the DEM simulation in MPa, $C I_{\text {in-situ }}$ is the measured average soil resistance from the in-situ tests in MPa and $n$ is the number of depth where the soil resistance values were measured ( $\mathrm{n}=15$ in this case). In the later sections these trendlines were compared with the measured average values of the penetration resistance.

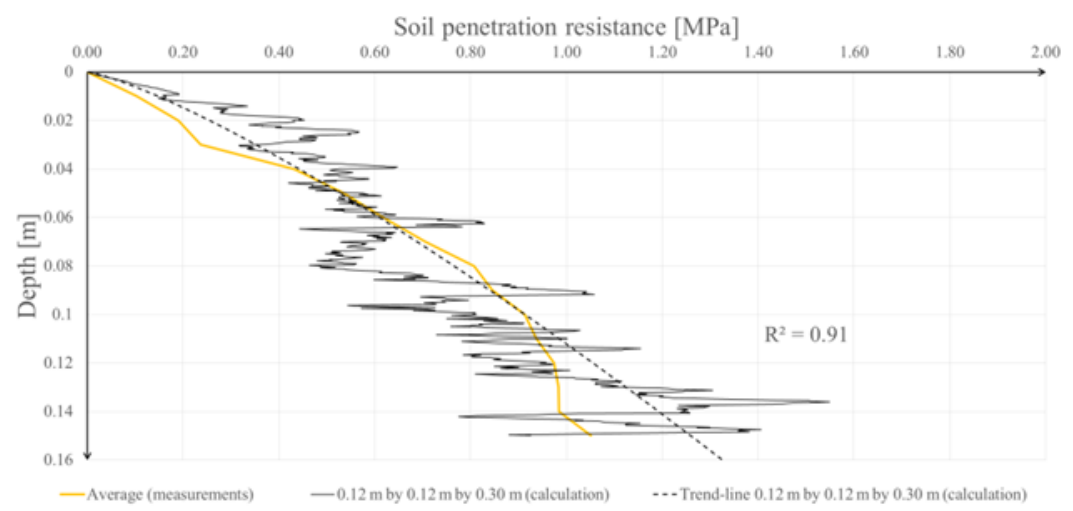

Figure 4. Variation in the discrete element method (DEM) simulation of the penetration test, shown for a rectangular cross section model with a crosssection of $0.12 \mathrm{~m}$ by $0.12 \mathrm{~m}$ and a height of $0.30 \mathrm{~m}$.

\subsection{Numerical simulation of the direct shear tests}

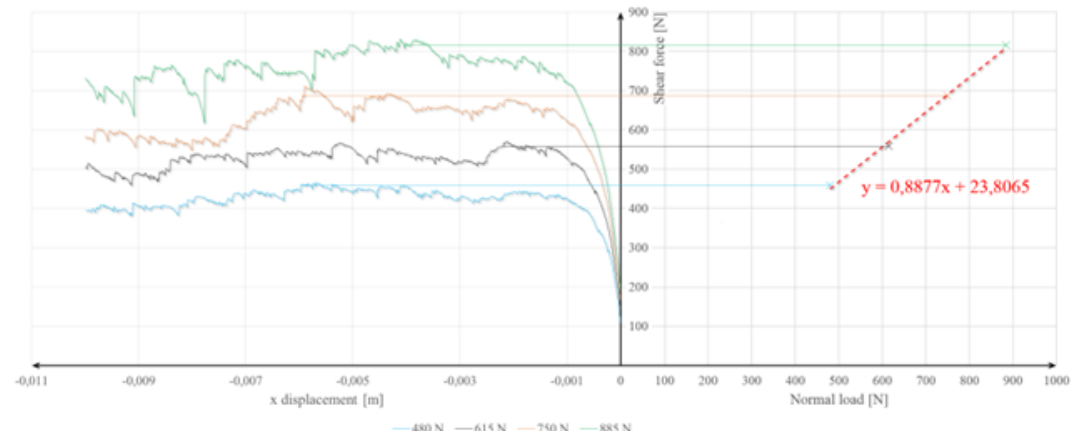

(a)

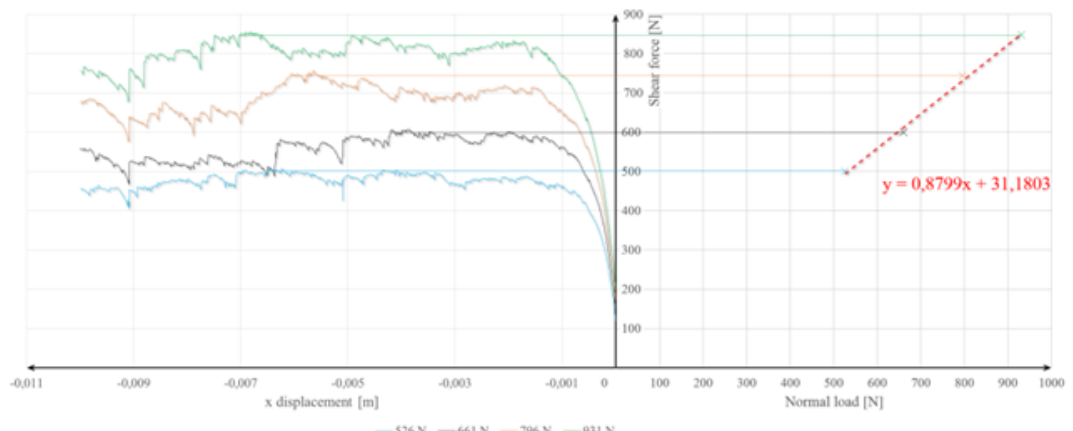

(b)

448 Figure 5. The force-displacement relationship calculated from the discrete 449 element method (DEM) simulation of the direct shear tests for the bottom 450 (a) and top (b) sections of the soil model. 
Figure 5 shows the DEM calculated force-displacement relationship of the direct shear tests for the bottom and top soil sections. The value of the shear force fluctuated similar to the work of Tamás et al (2013) and to the soil resistance in the 3D DEM simulations of penetration (Fig. 4). In order to calculate the mean of the maximum shear force, the force values were averaged in the $0.00025 \mathrm{~m}$ radius vicinity of the displacement where the maximum shear force takes place. From the mean of the maximum shear- and normal force values, the Coulomb line of the soil model layers can be drawn. Although the Coulomb line for the top and bottom layers are similar the cohesion component of the bottom layer $(8.66 \mathrm{kPa})$ was larger than that of the top layer $(6.61 \mathrm{kPa})$, while the friction angle was very similar $\left(41.34^{\circ}\right.$ and $\left.41.60^{\circ}\right)$, respectively. This result is in line (for cohesion only) with Mouazen and Neményi (1999) reported increase in the cohesion and internal friction angle values with depth.

Another result of the 3D DEM direct shear simulations is that the parallel bond's strength contact parameter does not have large effect on the calculated cohesion and angle of internal friction.

\subsection{The effect of the shape of the model's cross section}

The comparison between the DEM calculated (with both crosssection models) and field measured penetration resistance is shown in Fig. 6.

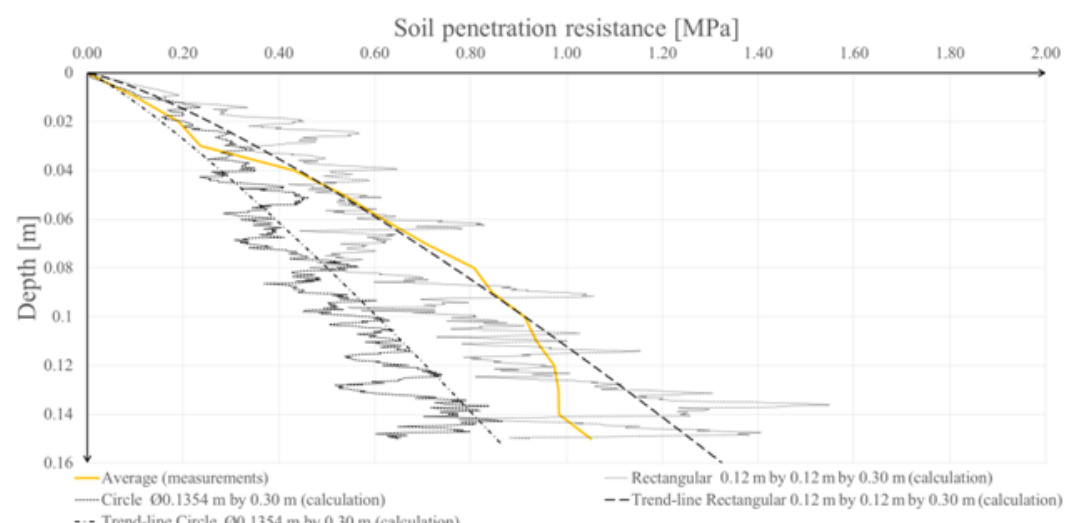

Figure 6. The effect of the discrete element model (DEM) soil model crosssection shape on calculated penetration resistance.

It can be clearly observed that the soil resistance calculated with the rectangular cross section is higher than that of the corresponding values calculated with the circular cross-section model. This can be explained by examining the distribution of the contact forces between the particles, shown in Fig. 7 for a rectangular model of $0.12 \mathrm{~m}$ by $0.12 \mathrm{~m}$ by $0.30 \mathrm{~m}$ and a circular model of $\varnothing 0.1354 \mathrm{~m}$ by $0.30 \mathrm{~m}$ and for a penetration depth of 
$486 \quad 0.78 \mathrm{~m}$ where simulations gave approximately the same soil 487 resistance value (see Fig. 6). The linewidth of the contact lines 488 is proportional to the magnitude of the force between the 489 particles. It was scaled up to $31 \mathrm{~N}$ in both cases, which means 490 that the greatest linewidth represents the contact force of $31 \mathrm{~N}$ 491 or higher between the contact elements. Figure 7 shows greater 492 contact forces near the tip of the penetrometer cone in the 493 rectangular cross-section model as compared to the circular 494 cross-section model, because there are more thick lines 495 (meaning greater contact forces) in the former case than in the 496 latter model. This can be possible because of the local damping 497 between the particles and because of the models' boundary 498 condition, namely the position of the side wall of the models. 499 The distance between the tip of the cone penetrometer and the 500 side wall is $0.12 / 2 \mathrm{~m}$ in the rectangular soil model, and $5010.1354 / 2 \mathrm{~m}$ in the circular model. Therefore, in the case of the 502 circular model a larger distance to the wall exists, so that the 503 effect of the cone's motion on particles stresses is lower, as the 504 particles have more freedom to move towards the wall as 505 compared to the rectangular model. This can cause smaller 506 calculated soil resistance in case of the circular cross-section 507 model as compared to that of the rectangular one with same 508 area ratio (same volume). 

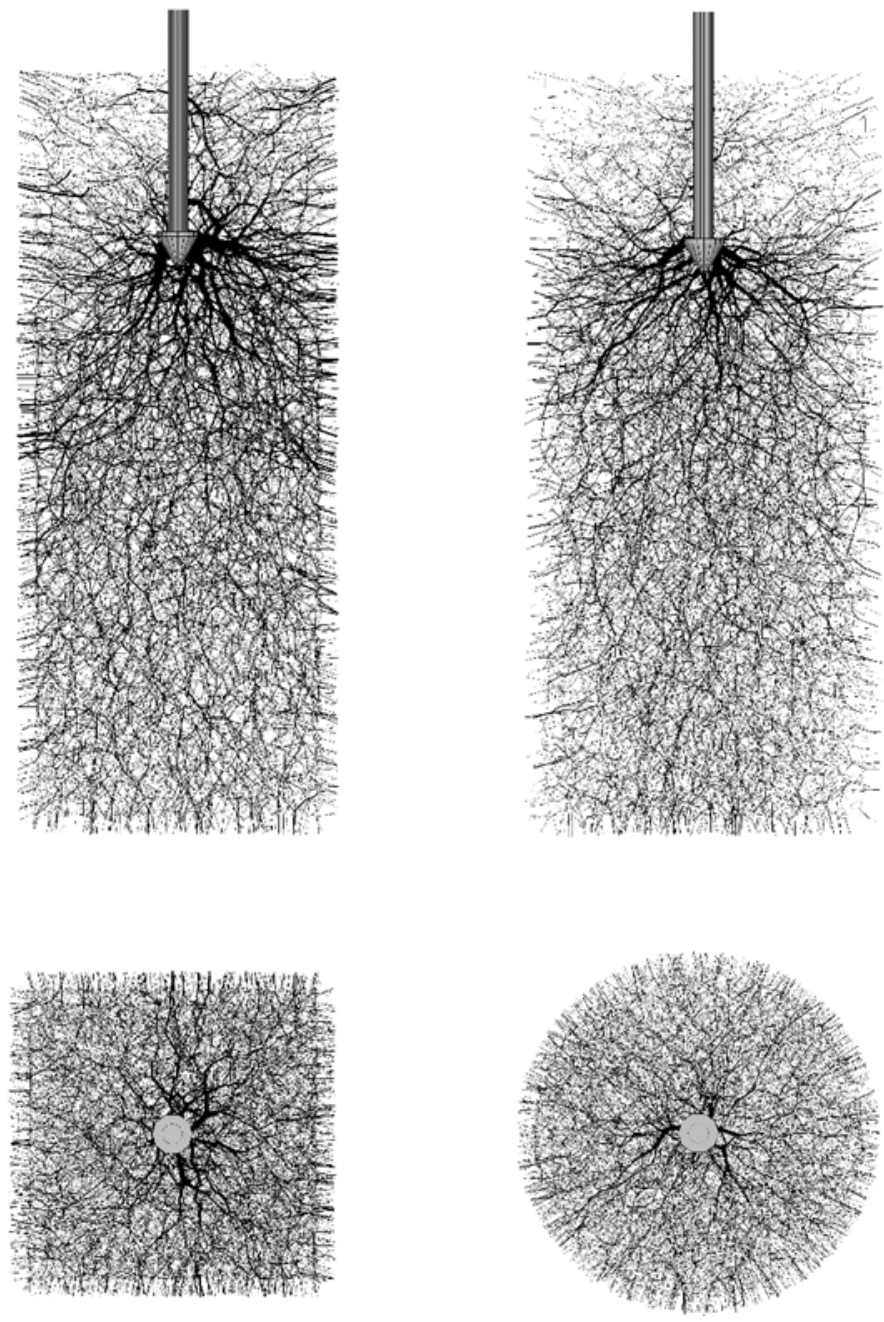

Figure 7. The distribution of the contact forces calculated with the discrete element method simulation for a rectangular (left -

$0.12 \mathrm{~m}$ by $0.12 \mathrm{~m}$ by $0.30 \mathrm{~m}$ ) and circular cross-section (right $\varnothing 0.1354 \mathrm{~m}$ by $0.30 \mathrm{~m}$ ) models of the same volume.

3.5. The effect of the size of the soil model's cross section
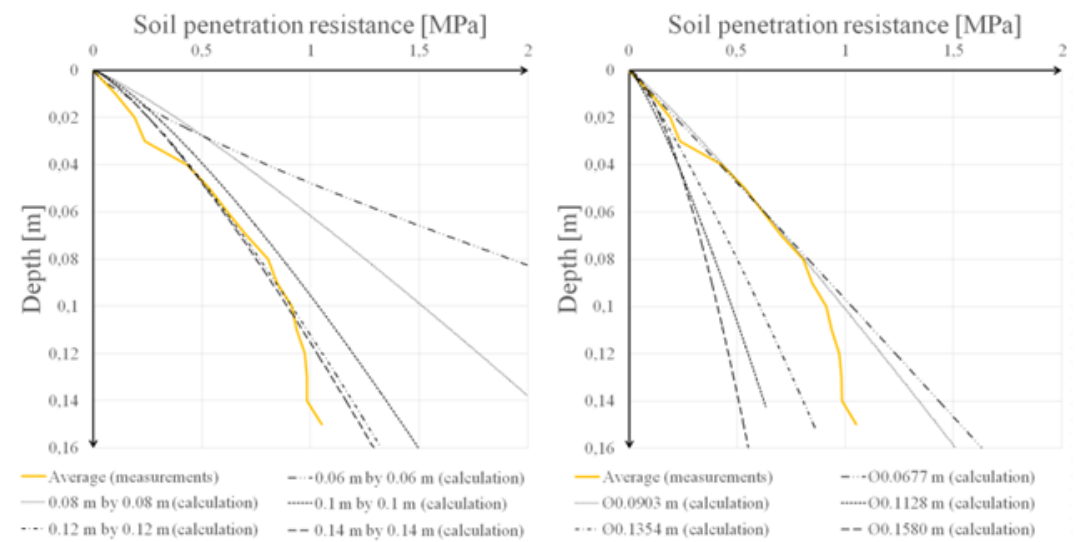

Figure 8 . The effect of the discrete element model (DEM) model cross section size on calculated penetration resistance calculated for the rectangular shape (left) and for the circular shape soil models (right). 
Figure 8 shows the results of the effect of the cross section size on penetration resistance, calculated from the DEM for the rectangular and circular cross-section models. In case of the smaller cross section models, the penetration resistance values were larger in both soil model shapes than that of the larger cross section models, because the boundary walls were too close so that the balls were constrained from moving away from the head of the cone penetrometer. In case of rectangular cross section model, the DEM simulations with area ratio of 50 , 72 and 98 (cross section size of $0.10 \mathrm{~m}$ by $0.10 \mathrm{~m}$, $0.12 \mathrm{~m}$ by $0.12 \mathrm{~m}$ and $0.14 \mathrm{~m}$ by $0.14 \mathrm{~m}$, respectively, see Table 3) resulted in similar but smaller soil resistance values than that of a cross section of $0.06 \mathrm{~m}$ by $0.06 \mathrm{~m}$ and $0.08 \mathrm{~m}$ by $0.08 \mathrm{~m}$ (Fig. 8). It could be concluded that either rectangular model with area ratio of 72 and 98 approximate the measured soil resistance with reasonable accuracy with mean relative errors of $14.91 \%$ and $16.69 \%$, respectively (Table 4).

Table 3. The geometrical parameters of the three dimensional (3D) discrete element soil models.

\begin{tabular}{ccc}
\hline $\begin{array}{c}\text { Size of the cross section } \\
{[\mathrm{m}]}\end{array}$ & $\begin{array}{c}\text { Area } \\
{\left[\mathrm{m}^{2}\right]}\end{array}$ & $\begin{array}{c}\text { Area ratio } \\
{[-]}\end{array}$ \\
\hline $\begin{array}{c}0.06 \text { by } 0.06 \\
\varnothing 0.0677\end{array}$ & $0.36 \mathrm{e}-2$ & 18 \\
$\begin{array}{c}0.08 \text { by } 0.08 \\
\varnothing 0.0903\end{array}$ & $0.64 \mathrm{e}-2$ & 32 \\
$\begin{array}{c}0.10 \text { by } 0.10 \\
\varnothing 0.1128\end{array}$ & $1.00 \mathrm{e}-2$ & 50 \\
$\begin{array}{c}0.12 \text { by } 0.12 \\
\varnothing 0.1354\end{array}$ & $1.44 \mathrm{e}-2$ & 72 \\
$\begin{array}{c}0.14 \text { by } 0.14 \\
\varnothing 0.1580\end{array}$ & $1.96 \mathrm{e}-2$ & 98 \\
\hline
\end{tabular}

\begin{tabular}{ccc}
\hline $\begin{array}{c}\text { Model's height } \\
{[\mathrm{m}]}\end{array}$ & $\begin{array}{c}\text { Penetration } \\
\text { depth } \\
{[\mathrm{m}]}\end{array}$ & $\begin{array}{c}\text { Height } \\
\text { ratio } \\
{[-]}\end{array}$ \\
\hline 0.20 & & 1.33 \\
0.25 & 0.15 & 1.67 \\
0.30 & & 2.00 \\
0.35 & & 2.33 \\
\hline
\end{tabular}

Table 4. The mean error of the DEM penetration simulations.

\begin{tabular}{ccccc}
\hline $\begin{array}{c}\text { Cross section } \\
\text { dimension }\end{array}$ & $\begin{array}{c}\text { Area } \\
\text { ratio }\end{array}$ & $\begin{array}{c}\text { Height } \\
\text { ratio }\end{array}$ & $\begin{array}{c}\text { Coefficient of } \\
\text { determination } \\
\left(\mathrm{R}^{2}\right)\end{array}$ & $\begin{array}{c}\text { Mean } \\
\text { relative } \\
\text { error }\end{array}$ \\
\hline$(\mathrm{m})$ & $(-)$ & $(-)$ & $(-)$ & $(\%)$ \\
\hline 0.06 by 0.06 by 0.30 & 18 & 2.00 & 0.89 & 152.19 \\
0.08 by 0.08 by 0.30 & 32 & 2.00 & 0.91 & 78.81
\end{tabular}




\begin{tabular}{lllll}
0.10 by 0.10 by 0.30 & 50 & 2.00 & 0.89 & 27.94 \\
0.12 by 0.12 by 0.20 & 72 & 1.33 & 0.87 & 14.74 \\
0.12 by 0.12 by 0.25 & 72 & 1.67 & 0.76 & 31.99 \\
0.12 by 0.12 by 0.30 & 72 & 2.00 & 0.91 & 14.91 \\
0.12 by 0.12 by 0.35 & 72 & 2.33 & 0.85 & 22.13 \\
0.14 by 0.14 by 0.30 & 98 & 2.00 & 0.84 & 16.69 \\
\hline$\varnothing 0.0677$ by 0.30 & 18 & 2.00 & 0.90 & 15.06 \\
$\varnothing 0.0903$ by 0.30 & 32 & 2.00 & 0.86 & 14.92 \\
$\varnothing 0.1128$ by 0.30 & 50 & 2.00 & 0.87 & 42.24 \\
$\varnothing 0.1354$ by 0.20 & 72 & 1.33 & 0.77 & 30.10 \\
$\varnothing 0.1354$ by 0.25 & 72 & 1.67 & 0.84 & 31.63 \\
$\varnothing 0.1354$ by 0.30 & 72 & 2.00 & 0.92 & 28.05 \\
$\varnothing 0.1354$ by 0.35 & 72 & 2.33 & 0.93 & 34.03 \\
$\varnothing 0.1580$ by 0.30 & 98 & 2.00 & 0.91 & 45.01 \\
\hline
\end{tabular}

540

541 According of Fig. 8 for the simulation with the circular cross

542 section soil model, similar tendency of results to that of the

543 rectangular shape model could be observed. The highest

544 penetration resistance was observed with the smallest cross

545 section size model, which reduced with the increase in the cross

546 section size. However, a minor deviation was observed for the

547 resistance calculated for the area ratios between 50 and 72 ,

548 where although very similar results were observed a slightly

549 greater resistance was calculated for the latter case. This can be

550 interpreted by the geometrical differences between the

551 simulations, namely the different ball positions and ball

552 radiuses. It is possible that the cone does not get into contact

553 with so many particles in one simulation than it does in the

554 other, which affects its calculated resistance. For the circular

555 models with area ratio of 50,72 and 98 , the calculated

556 penetration resistance variations with depth were smaller than

557 the in-situ measured variations, which suggests that these

558 models are not useful for approximating the measured

559 penetration resistance. The best DEM model that can be

560 recommended to approximate the in-situ measurement is the

561 model with area ratio of 32 with a mean relative error of

$562 \quad 14.92 \%$ (Fig. 8 and Table 4), after which the model with area

563 ratio of 18 is considered as the second best performing model

564 with a mean relative error of $15.06 \%$.

565 Our expectation was that if the size of the cross section of the

566 soil model is increased the soil penetration resistance should

567 decrease because the freedom of the elements' movement

568 increases. But, if the cross section size is large enough and

569 subsequently the area ratio then the DEM simulation results

570 should not change anymore because the boundary of the model 
571 is far away enough to have an effect on penetration resistance.

572 Therefore, the rectangular and circular soil body should give

573 similar results in penetration resistance. According to the

574 results in the former section the circular models always gave

575 smaller soil resistance values than that of the rectangular soil

576 models. This means that there is an effect of the soil body

577 boundary in case of soil model with the greatest area ratio (98).

578 This can be seen in Fig. 9 where the soil penetration resistance

579 at depth of $0.15 \mathrm{~m}, 0.10 \mathrm{~m}, 0.05 \mathrm{~m}$ (e. g., CI index) were

580 illustrated as the function of area ratio (e. g., the size of the

581 models cross section) in case of rectangular shape (left) and

582 circular shape soil models (right), respectively. In case of

583 rectangular shape the coefficient of determination value were

584 high $(>0.93)$ and the penetration resistance decreased with

585 increasing area ratio but it can be smaller because the trend-

586 lines were not approximate their asymptotes with sufficient

587 accuracy. Similar to that can be said in case of circular model

588 shape where the $\mathrm{R}^{2}$ values of trend-line fitting were smaller

589 than in the former case. Therefore, the area ratio should be

590 increased but in this case more particles are needed to perform

591 the simulation and this will increase the computational time

592 dramatically in the future. In such simulations one should

593 expect the need for several million elements, which will cause

594 unacceptable computational time and the simulations will be no 595 more useful.
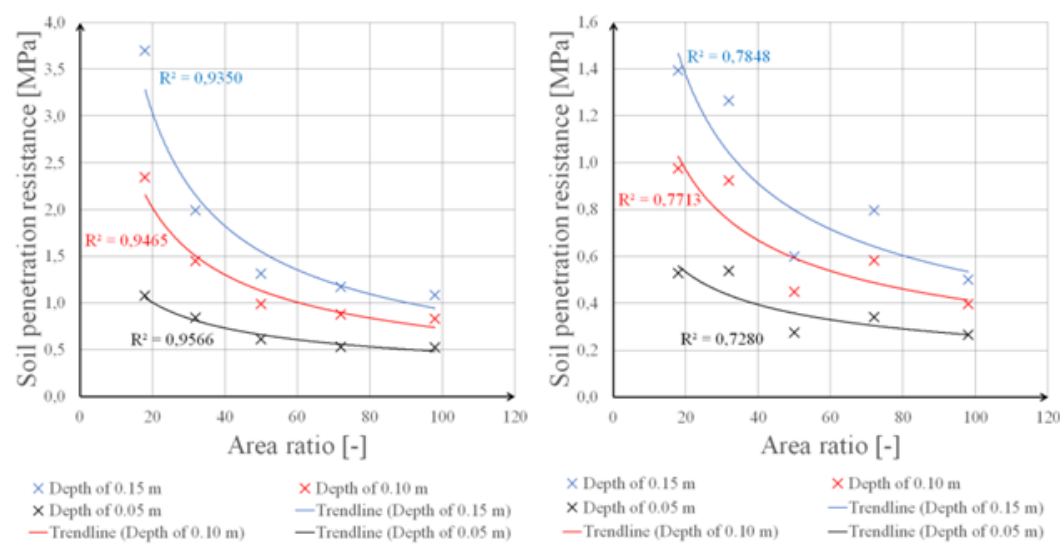

Figure 9. The effect of the discrete element method (DEM) model cross section size on penetration resistance calculated for the rectangular shape (left) and for the circular shape soil models (right).

Summarizing the results it can be said that the best approximating DEM soil model to the in-situ penetration resistance measurements was the rectangular model with area ratio of 72 (a mean relative error of $14.74 \%$ ). However the mean error of the best performing circular model (with area ratio of 32) was slightly smaller than that of the rectangular model with area ratio of 72 (see Table 4). The advantage of the 
circular cross section models was that they gave accurate results with smaller area ratio (smaller volume) than the rectangular models did. Therefore, from practical point of view, it is recommended to adopt the circular shaped models, since smaller number of particles need to be used in the simulation and the calculation time can be minimized, as this depends on the number of the elements (Hanley et al, 2014).

\subsection{Effect of soil model's height}

As stated earlier that the DEM simulations were performed with height ratios of $1.33,1.67,2$ and 2.33 to analyse the effect of the model's height on calculated penetration resistance. The results of these simulations for the rectangular and circular cross section models are shown in Fig. 10 a and b, respectively. It can be observed that the model's height does not have considerable effect on the calculated soil penetration resistance at the range of height ratio between 1.33 and 2.33. Therefore similar conclusion can be drawn to that of the former section, that from practical point of view, it is recommended to adopt the smallest height ratio of 1.33 , since smaller number of particles are need to be used in this simulation and the calculation time can be minimized.
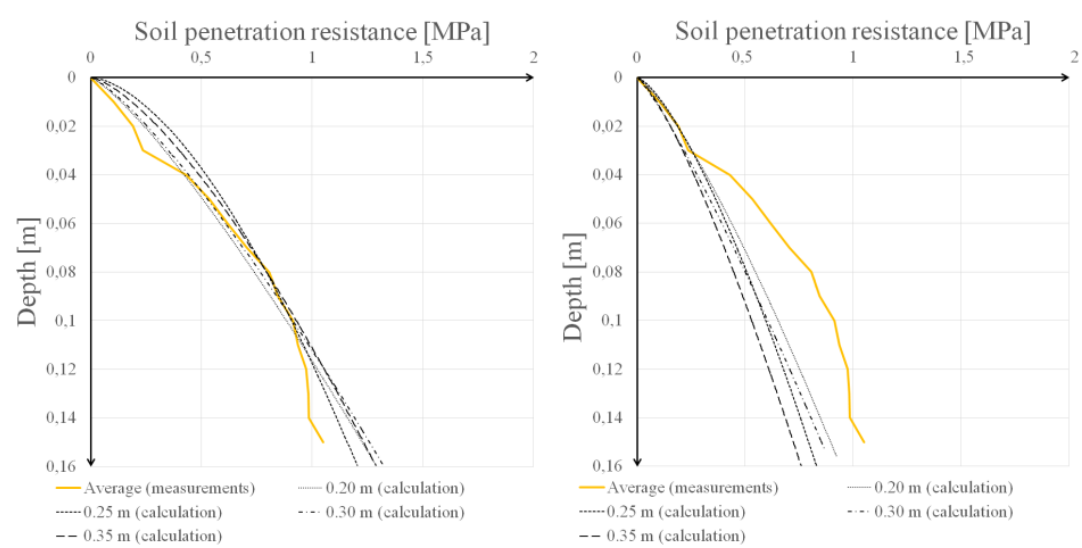

Figure 10. The effect of the discrete element model (DEM) model height on calculated penetration resistance for the rectangular (left) and circular (right) cross section soil model.

\section{Conclusions}

This paper used the discrete element method (DEM) to simulate the penetration of a slightly cohesive soil with a standard cone penetrometer, aiming at optimising the soil model geometry for the best estimations of penetration resistance that match the corresponding in-situ measurements. After the calibration of the contact properties of the discrete element model the soil mechanical properties, namely, cohesion and internal friction angle were estimated by DEM simulation of direct shear box tests. 
642 Results showed that the DEM can be successfully used to

643 simulate the penetration in a cohesive soil, as the DEM

644 calculations were in good agreement with the measured values.

645 The DEM calculations of the penetration resistance, calculated

646 with the circular cross section soil model were always smaller

647 than those calculated with the rectangular model. The DEM

648 model outputs with the rectangular cross section showed that

649 the model with an area ratio of 72 (cross section =

$6500.12 \mathrm{~m}$ by $0.12 \mathrm{~m}$ ) or 98 (cross section $=0.14 \mathrm{~m}$ by $0.14 \mathrm{~m}$ )

651 provided the most accurate estimation of penetration resistance

652 with a mean relative error of $14.91 \%$ and $16.69 \%$, respectively

653 when compared to the in-situ measurement. For the circular

654 cross section model, the model with an area ratio of 32

655 (diameter $=\varnothing 0.0903 \mathrm{~m})$ followed by 18 (diameter $=$

$656 \varnothing 0.0677 \mathrm{~m})$ performed the best with mean relative errors of

$657 \quad 14.92 \%$ and $15.06 \%$, respectively when compared to the in-

658 situ measurement. The DEM simulations of the optimal height

659 ratio showed the model's height have a negligible effect on the

660 calculated soil penetration resistance in the range of height ratio

661 between 1.33 and 2.33. Therefore, it is possible to recommend

662 these DEM model parameters as the best results of DEM

663 simulation of soil penetration with a standard cone

664 penetrometer.

\section{Acknowledgement}

666 The authors gratefully acknowledge the assistance of the staff 667 of Szent István University of Gödöllö for provide the results of 668 their in-situ penetration tests.

\section{References}

670 Arroyo, M., Butlanska, J., Gens, A., 2009. Homogeneity and

671 Symmetry in DEM Models of Cone Penetration. Power and Grains:

672 proceedings of the 6th international conference on micromechanics

673 of granular media; AIP Conf. Proc. 1145, 425-428.

674 Bentaher, H., Ibrahmi, A., Hamza, E., Hbaieb, M., Kantchev, G., 675 Maalej, A., Arnold, W., 2013. Finite element simulation of 676 moldboard-soil interaction. Soil \& Tillage Research, 134, 11-16.

677 Butlanska, J., Arroyo, M., Gens, A., O’Sullivan, C., 2014. Multi678 scale analysis of cone penetration test (CPT) in a virtual calibration 679 chamber. Canadian Geotechnical Journal, 51 (1), 51-66.

680 Chen, Y., Munkholm, L. J., Nyord, T., 2013. A discrete element 681 model for soil-sweep interaction in three different soils. Soil \& 682 Tillage Research, 126, 34-41. 
Chi, L., Kushwaha, R. L., 1990. A non-linear 3-d finite element analysis of soil failure with tillage tools. Journal of Terramechanics, 27(4), 343-366.

Cundall, P. A., Strack, O. D. L., 1979. Discrete numerical model for granular assemblies. Geotechnique, 29(1), 47-65.

Falagush, O., McDowell, G. R., Yu, H., 2015. Discrete Element Modeling of Cone Penetration Tests Incorporating Particle Shape and Crushing. International Journal of Geomechanics, 10.1061/(ASCE)GM. 1943-5622.0000463, 04015003.

Fervers, C. W., 2004. Improved FEM simulation model for tire-soil interaction. Journal of Terramechanics, 41, 87-100.

Fleige, H., Horn, R., 2000. Field experiments of the effect of soil compaction on soil properties, runoff, interflow and erosion. In: Horn, R., et al. (Eds.), Subsoil Compaction Distribution, Processes and Consequences. Advance in GeoEcology, 32, Catena Verlag, Reiskirchen, Germany, 258-268.

Formato, A., Faugno, S., Paolillo, G., 2005. Numerical Simulation of Soil-plough Mouldboard Interaction. Biosystems Engineering, 92(3), 309-316.

Foster Jr., W. A., Johnson, C. E., Chiroux, R. C., Way, T. R., 2005. Finite element simulation of cone penetration. Applied Mathematics and Computation, 162, 735-749.

Fountas, S.; Paraforos, D.; Cavalaris, C.; Karamoutis, C.; Gemtos, T. A.; Abu-Khalaf, N.; Tagarakis, A., 2013. A five-point penetrometer with GPS for measuring soil compaction variability. Computers and Electronics in Agriculture, 96, 109-116.

Garner, T. H., Reynolds, W. R., Musen, H. L., Miles, G. E., Davis, J. W., Wolf, D., Peiper, U. M., 1987. Energy Requirement for Subsoiling Coastal Plain Soils. Transactions of The American Scociety of Agricultural Engineers, 30(2), 343-350.

Goda, T. J., Ebert, F., 2005. Three-dimensional discrete element simulations in hoppers and silos. Powder Technology, 158, 58-68.

Hamza, M. A.; Anderson, W. K., 2005. Soil compaction in cropping systems. A review of the nature, causes and possible solutions. Soil \& Tillage Research, 82, 121-145.

Hanley, K. J., Huang, X., O’Sullivan, C., Kwok, F. C. Y., 2014. Effect of sample size on the response of DEM samples with a realistic grading. Particuology, 15, 107-115.

Itasca, 1999. PFC2D theory and background manual. Version 2.0. Available from: http://www.itascacg.com

Keppler, I., Oldal, I., Csizmadia, B., Fenyvesi, L., 2012. Outflow properties of silos: The effect of arching. Advanced Power Technology, 23, 290-297. 
Kerényi, Gy., 1996. A talaj vágásának modellezése végeselem

727 módszerrel (Modelling of Soil Cutting with Finite Element Method).

$728 \mathrm{PhD}$ thesis, Polytechnic University of Budapest, Budapest, Hungary

729 (in Hungarian).

730 Khot, L. R., Salokhe; V. M., Jayasuriya H. P. W., Nakashima, H., 731 2007. Experimental validation of distinct element simulation for 732 dynamic wheel-soil interaction. Journal of Terramechanics, 44, $733429-437$.

734 Knuth, M. A., Johnson, J. B., Hopkins, M. A., Sullivan, R. J., Moore, 735 J. M., 2012. Discrete element modeling of a Mars Exploration Rover 736 wheel in granular material. Journal of Terramechanics, 49, 27-36.

737 Laib, L. (Editor), 2002. Terepen mozgó járművek (Moving off-road 738 vehicles). Szaktudás Kiadó Ház, Budapest, Hungary (in Hungarian.)

739 Lin, J., Wu, W., 2012. Numerical study of miniature penetrometer in 740 granular material by discrete element method. Philosophical

741 Magazine, Volume 92, Issue 28-30.

742 Máthé, L., Kiss, P., Laib, L., Pillinger, Gy., 2013. Computation of 743 run-off-road vehicle speed from terrain tracks in forensic 744 investigations. Journal of Terramechanics, 50, 17-27.

Máthé, L., 2014. Közútról lefutó jármüvek mozgásának elemzése

746 (Analysis of the motion of vehicles running onto terrain). $\mathrm{PhD}$ thesis,

747 Szent István University of Gödöllö, Gödöllö, Hungary (in 748 Hungarian).

749

750

McKyes, E. 1985. Soil Cutting and Tillage. Elsevier, New York, USA.

Mouazen, A. M.; Neményi, M., 1998. A Finite element model of soil loosening by a subsoiler with respect to soil conservation. In: H.P. Blume et al. (Editors), Towards Sustainable Land Use, Advance in GeoEcology 31, Catena Verlag, Reiskirchen, Germany, 549-556.

Mouazen, A. M., Neményi, M., 1998. A review of the finite element modelling techniques of soil tillage. Mathematics and Computers in Simulation, 48 (1), 23-32.

Mouazen, A.M.; Neményi, M., 1999. Finite element analysis of subsoiler cutting in non-homogeneous sandy loam soil. Soil \& Tillage Research, 51, 1-15.

Mouazen, A.M.; Ramon, H., 2002. A numerical-statistical hybrid modelling scheme for evaluation of draught requirements of a subsoiler cutting a sandy loam soil, as affected by moisture content, bulk density and depth. Soil \& Tillage Research, 63, 155-165.

Nakashima, H., Fujii, H., Oida, A., Momozu, M., Kanamori, H., Aoki, S., Yokoyama, T., Shimizu, H., Miyasaka, J., Ohdoi, K., 2010. small lunar rover on sloped terrain. Journal of Terramechanics, 47, 307321 . 
771 Investigation of elemental shape for 3D DEM modelling of

772 interaction between soil and narrow cutting tool. Journal of

773 Terramechanics, 50, 265-276.

774 Potyondy, D. O., Cundall, P. A., 2004. A bonded-particle model for 775 rock. International Journal of Rock Mechanics \& Mining Sciences, 776 41, 1329-1364.

777 Sadek, M. A., Chen, Y., Liu, J. 2011. Simulating shear behavior of a 778 sandy soil under different soil conditions. Journal of Terramechanics, $779 \quad 48,451-158$.

780 Smith, W., Peng, H., 2013. Modeling of wheel-soil interaction over 781 rough terrain using the discrete element method. Journal of 782 Terramechanics, 50, 277-287.

783 Shmulevich, I., Asaf, Z., Rubinstein, D., 2007. Interaction between 784 soil and a wide cutting blade using the discrete element method. Soil 785 \& Tillage Research, 97, 37-50.

786 Sudduth, K. A.; Chung, S. O.; Andrade-Sanchez, P.; Upadhyaya, S. 787 K., 2008. Field comparison of two prototype soil strength profile 788 sensors. Computers and Electronics in Agriculture, 61(1), 20-31.

789 Tamás, K., Jóri, J. I., Mouazen, A. M., 2013. Modelling soil-sweep 790 interaction with discrete element method. Soil \& Tillage Research, 791 134, 223-231.

792 Tanaka H., Momozu M., Oida A., Yamazaki M., 2000. Simulation of 793 soil deformation and resistance at bar penetration by the Distinct 794 Element Method. Journal of Terramechanics, 37, 41-56.

795 Tekeste, M. Z., Raper, R. L., Tollner, E. W., Way, T. R., 2007. Finite 796 Element Analysis of Cone Penetration in Soil for Prediction of 797 Hardpan Location. Transactions of the ASABE, 50(1), 23-31.

798 Terzaghi, K., 1943. Theoretical Soil Mechanics. John Wiley and 799 Sons, New York.

800 Wang, J., Zhao, B., 2014. Discrete-continuum analysis of monotonic 801 pile penetration in crushable sands. Canadian Geotechnical Journal 802 51, 1095-1110. 